\title{
Research on the Course Construction and Teaching Mode of Internet of Things System Integration
}

\author{
WU JIAN FEI $1^{1,2, a,{ }^{*}}$ ，XU TIAN TIAN ${ }^{2, b}$ ，WANG HONG YI ${ }^{1, c}$
}

\author{
${ }^{1}$ College of Electronic and Engineering, National University of Defense Technology, Changsha, \\ China \\ 2Tianjin Binhai Civil-military Integrated Innovation Institute, Binhai, Tianjin, China \\ awujianfei990243@126.com, b1473551045@qq.com, cwanghongyi2011@163.com
}

Keywords: Internet of Things System Integration; Course construction; Teaching mode

\begin{abstract}
Nowadays, Internet of Things (IOT) is used more and more widely, and exhibited a sustained hot situation. IOT is China's strategic emerging industries, involving computer control, wireless communications, optical communications, network, software, information security and other fields. Colleges and universities should set up IOT profession with the purpose to cultivate high-tech IOT industry application talents. It is an interdisciplinary and comprehensive new profession which covering information perception, transmission, processing and other key technologies. This article is combined with the teaching situations of current three colleges and universities which have set up the IOT Engineering courses. The IOT system integration courses from the curriculum system, teaching models and other aspects are discussed and researched.
\end{abstract}

\section{物联网系统集成课程建设与教学模式研究}

\author{
吴建 1 $^{1, a^{*}}$, 徐甜甜 $2, b$, ,王宏义 ${ }^{1, c}$ \\ 1 国防科学技术大学电子科学与工程学院, 长沙, 湖南, 中国 \\ 2天津市滨海新区军民融合创新研究院, 滨海, 天津, 中国
}

awujianfei990243@126.com, b1473551045@qq.com, cwanghongyi2011@163.com

关键词: 物联网工程; 课程体系建设; 教学模式研究

中文摘要. 物联网在当今的使用范围越来越广, 并且表现出持续大热的形势。物联网是我国战 略性新兴产业, 其技术涉及计算机控制、无线通信、光通信、网络、软件、信息安全等多个 领域。各高校应招开设物联网专业, 目的是培养高技能的物联网行业应用型人才, 它是涵盖 信息感知、传输、处理等关键技术的跨学科、综合性的新型专业。本文结合当前国内三大高 校设置的物联网工程专业课程教学情况, 对物联网工程专业从课程体系建设、教学模式等方 面对其进行探讨与研究。

\section{一、前言}

2008 年 IBM 提出的 “智慧地球” 被奥巴马政府采纳, 并将这一概念提升到国家级发展战 略, 一场关于物联网的风暴席卷了全球。物联网即 “物物相连的互联网”。继美国欧盟日本 之后, 2009 年 8 月, 温家宝总理在视察无锡的中科院物联网技术研发中心时, 提出要把无锡 建设成 “感知中国” 中心。2010 年温家宝总理在第十一届人大三次会议上所作的政府工作报 告中对物联网定义是 “物联网是指通过信息传感设备, 按照约定的协议, 把任何物品与互联 
网连接起来, 进行信息交换和通信, 以实现智能化识别、定位跟踪、监控和管理上的一种网 络”。2011 年国家发布了物联网 “十二五” 的发展规划, 这将我国的 “物联网” 的研究与开 发推入了高潮 ${ }^{[1]}$ 。

伴随着智慧城市、车联网, 工业物联网，智慧医疗等行业的发展，IOT 迅猛发展。美国发 布的 2016-2045 年新兴科技趋势报告中把物联网排在第一。在 2045 年, 最保守预测将会有超 过 1 千亿设备连接在网络上, 包括移动设备、可穿戴设备、家用电器、医疗设备、工业探测 器、监控摄像头、汽车以及服装等。他们所创造并分享的数据将会给我们的工作和生活带来 一场新的信息技术产业革命, 这涵盖了大量现有的传统专业和技术体系 ${ }^{[2]}$ 。但无论数量还是质 量, 现有的物联网专业人才都不能满足产业转型升级的需求。因此, 培养物联网工程专业人 才已十分重要, 自 2010 年 3 月教育部对各高校发出建立物联网专业学科的号召, 各高校纷纷 提交申请。目前, 全国已经开设了物联网专业的高校有不少, 但对该专业的教学研究尚处于 起步阶段, 还没有形成非常完整的教学理论与实施体系。结合已有几大高校的实际情况, 从 专业的教学目标、课程体系规划、相关实训室建设、师资建设等方面对其进行探讨与研究。

\section{二、三所高校物联网专业相关探讨}

\section{1、南开大学的物联网专业建设}

南开大学的吴功宜教授提出 “课程精, 实验强” 的教学原则。他认为物联网工程专业教 学计划与专业课程设置上, 一定要处理好与已经形成规模的计算机专业课程体系之间的关 系。毕竟学校要在短时间内开设一门新的课程, 在教材建设、实验室建设以及师资准备上, 都是不现实的。所以吴功宜教授提出 “充分利用和发挥各个大学的已有的专业优势, 扬长避 短, 在满足共性要求的基础上, 形成不同学校在物联网工程专业建设中的特色” 这一理念 [3]。

他将物联网工程专业课程建设大致分为两部分内容, 一部分是计算机学科的基础课程, 另一类则是体现物联网工程专业特点的专业课课程。物联网工程专业课程大致包括介绍物联 网基本概念; 感知层知识与技术; 物联网中的无线通信技术; 物联网应用系统设计; 物联网 智能控制与信息处理技术以及物联网信息安全技术等 ${ }^{[3]}$ 。

他还着重强调了与理论教学相辅相成的实验教学环境的建设的重要性。他提出实验教学 环境的建设, 是能不能做到 “课程精, 实验强” 和建设物联网工程专业的关键 ${ }^{[3]}$ 。

\section{2、武汉大学的物联网专业建设}

武汉大学依照 “三创”（创新、创造、创业）人才培养理念, 依托已有的计算机学科平 台, 想以此培养出具有扎实计算机基础, 又有物联网工程技术特长的复合型应用人才。学校 将物联网工程专业的课程体系建设分为两部分：课程模块规划和专业核心课程建设。

课程分为 8 个模块: 基础模块、感知模块、网络与通信模块、数据处理模块、安全模块、 领域应用开发模块、信息服务模块和实践模块。

核心课程: 物联网工程导论、物联网通信技术、传感器原理及应用、RFID 原理及应 用、传感器网络及应用、物联网软件设计、物联网数据处理、物联网应用系统设计、传感器 微操作系统原理与设计、物联网工程规划与设计、RFID 系统综合设计、物联网应用系统综 合设计等 ${ }^{[4]}$ 。

学校还提出重点发展物联网技术实践教学的观念。物联网实践教学的设计和开展均按从 基础到综合的理念递阶进行的, 除计算机基础类课程实验外, 还专门针对物联网工程专业学 生, 设计了包括 EDA 综合设计、无线传感器网络综合设计、RFID 系统综合设计等专业类实 验课程 ${ }^{[5]}$ 。

\section{3、安庆师范大学的物联网专业建设}

从学科建设的角度, 安庆师范大学以计算机科学与技术、信息管理与信息系统和通信工 
程三个专业为依托, 重复利用各个专业的教学资源建设新专业。这样也构成了互相交叉, 共 同发展的学科群。他们将物联网课程体系分为四个部分：公共课、专业基础课、专业方向课 和专业拓展课。

公共课可以强化学生对职业道德的关注。专业基础课则通过主干课程，使学生掌握物联 网专业的基础理论知识。而所谓的专业方向课则是学校为学生拟定的两个专业方向：物联网 理论、物联网工程。其中物联网理论方向会让学生掌握物联网技术相关的理论知识; 物联网 工程方向则会让学生掌握物联网建设相关的技术知识, 为将来技术类工作打下基础。专业方 向课是为了让学生根据自身特点, 自寻选择。专业拓展课是学生可以有选择地学习的课程, 其目的是拓宽学生知识面, 使学生适应这种各个领域技术在一定程度上交互渗透、互为补充 的现状 ${ }^{[6]}$ 。

学校也提出了 “实践教学也是教学体系的重要组成部分” 这一观点。在校期间, 让学生 在学习各课程的理论知识后, 通过在各种实验室模拟操作、现场实践等方式而使知识重新整 合系统化, 使学生有较好的现场操作能力。还组织学生通过校企合作的方式, 让学生进入企 业, 利用企业的实训基地和实训设备, 参与到实际项目中去, 加强专业技能培养 ${ }^{[7]}$ 。

\section{三、对比与结论}

\section{1、分析与对比}

经过对以上三所高校物联网专业的研究和探讨，不难发现他们之间的相同点和不同点。

在专业的初始建立时，以上三所学校都没有盲目的去建设一个新的专业，都是以自身本 有的相关专业-一计算机专业等为依托，建立新专业。这一点为专业打下坚实的地基。在课程 建设方面, 三所高校对实验室的建设与实践教学都十分看重。实践教学注重于对学生的锻炼, 加强专业技能培养, 会让他们更快的理解书本的知识, 对学生未来的就业也有着不可估量的 作用。

但在课程的处理上则不尽相同, 武汉大学将课程分为 8 个模块; 安庆师范大学将课程分 为四个部分 (公共课、专业基础课、专业方向课和专业拓展课); 而南开大学教授则提出先分 为两个大方向, 作为物联网专业依托的计算机专业基础课程和物联网专业的特色课程。又将 物联网专业特色课程大致分为物联网基本概念, 感知层, 无线通信, 物联网应用系统, 信息 处理，与信息安全这 6 个方向。

\section{2、结论}

虽然看起来三所高校对于物联网专业的课程建设是不尽相同的，但是从本质上来说，都 是一样的。本着求同存异的原则, 通过上面的相关研究和探讨, 我认为在物联网专业的建设 方面要注意以下几点。

第一，专业的定位需准确。由于物联网专业技术门类差异大，所以在专业建立初期，需 要分析相关岗位及人才市场需求, 其他高校的专业发展方向。以分析结果来进行专业建设, 充分考虑学生的就业需要; 与其他院校对比交流, 取长补短, 形成不同于其他学校的物联网 特色工程, 增强学生的就业竞争力。

第二,从学科建设的角度，重复利用学校已有专业的教学资源建设新专业。使各专业之 间互相交叉，共同发展。

第三，创新教学模式，制定课程标准。

“教学做一体化” 教学模式是由我国教育家陶行知提出的, 他指出 “教、学、做”在教 学过程中是一体的, “做” 是核心, 教学都要围绕 “做” 来开展。我非常赞同这个观点。它将 理论教学与实践教学融合在一起, 提高课堂教学质量, 充分调动学生的积极性, 在动手中将 书本知识与实践完美的结合, 能够有效的解决现在应届毕业生空有理论而动手能力不足的问 题。这样的教学模式才更贴合培养应用技术型人才的专业定位。

为了培养出能够从初期设计、开发到后期维护的高能力人才。可以将物联网专业课程分 
为三个模块: 基础课程、专业核心课程和实践实训课程。专业核心课程的学习是以基础课程 作为支撑的, 因此, 我们要依据专业核心课程来设置基础课程。物联网可以分成三个层次: 应用层、通信层和感知层，所以物联网的核心课程则涵盖了传感技术、接入技术、网络技术、 应用技术和安全技术等。为此作为支撑的基础课程, 则需要学习 $C$ 语言、单片机应用、电路 基础、数据库管理等底层技术。实践实训课程则全面围绕核核心课程展开, 实践课就是让学 生将学到的知识融入到项目中去, 有效地掌握物联网工程项目的核心技能, 比如传感器技术、 RFID 技术等。实践课还使学生初步学会了使用和调试物联网工程中的相关设备。

要很好的实施 “教学做一体化”，那高技能的教师队伍和全套的实验室也是不可或缺的。

第四, 高技能教师队伍的建立。教师的能力直接决定了课堂的教学质量。“教学做一体 化” 教学模式中, 课堂教学既包含理论, 又融合了实践, 对教师的要求很高, 培养或引进理 论与实践双结合的教师在专业建设过程中很重要。我们可以从物联网行业企业中引入的专业 人才; 让教师参加全国各地物联网专业教师集体培训; 也可以以学校名义外派专业教师到物 联网企业中顶岗锻炼，让其在工作中提高自身能力。

第五, 则是完善实验、实训室建设, 优化实践教学。要做到 “教学做一体化” 模式, 配套 的实验场所是不可缺少的。在课程期间, 穿插实验课来培养学生的应用和创新思维等能力, 灵活运用课上的知识。确立一个阶梯化的实践教学体系, 从基础实验, 综合实践, 到最后的 创新设计实践, 让知识层层叠加, 一步一个脚印的踏实前进。最后坚持校企合作，建立针对 职业岗位建立人才的培养模式, 针对岗位需求设置岗位课程, 在工作过程中整合理论知识, 利用企业的实训基地和实训设备, 参与到实际项目中去, 让学生们快速地进入角色, 加强专 业技能培养。提高人才培养的针对性和适应性。

总之, 开设物联网专业, 是机遇也是挑战。我们要不断更新观念, 改革创新, 不断加强 教师队伍的建设, 提高专业教学水平, 就一定能培养出更多应用技术型人才, 为物联网产业 的快速发展添砖加瓦。

\section{References}

[1] Wang Qing, A Probe into Development of IOT and Higher Vocational Education[J], Nantong Vocational \& Technical Shipping College, 2010(3).

[2] Peng Ling, Discussion and Research on Professional Construction of Internet of Thing in Colleges[J], GuangDong University of Science\&Technology, 2013.

[3] WU Gong-yi, Thinking of the Professional Curriculum System of the Internet of Things[J], Nankai University, 2010.

[4] $\mathrm{Yu} \mathrm{Li}$, Research on Construction and Practical Teaching of Internet of Things[J], Wuhan University School of Computer Science, 2013.

[5] Shi Ke, Research on the Course Construction of Internet of Things Technology[J], Huazhong University of Science and Technology, 2014.

[6] Liu Guijiang, Research and Discussion of Things Specialty in Training Program[J],Anqing Teachers College,2011.

[7] Wang Zhiliang, Discipline Construction and Teaching Practice of Internet of Things[J], Beijing University of Science and Technology, 2012(10). 